\title{
Innovation as a Driver of the Sustainable Healthcare Systems: The Case of Romania
}

\author{
Adela Coman and Ana-Maria Grigore
}

Faculty of Business and Administration, University of Bucharest,Romania

Correspondence should be addressed to: Adela Coman; adela.coman@faa.unibuc.ro

Received date: 14 December 2016; Accepted date: 29 March 2017; Published date: 29 May 2017

Academic Editor: Irina Boncea

Copyright (C 2017. Adela Coman and Ana-Maria Grigore. Distributed under Creative Commons CCBY 4.0

\begin{abstract}
This paper deals with the problem of sustainability of the healthcare systems and how innovation can contribute to achieving better results with lower costs. We have drawn a conceptual framework by reviewing the relevant literature on innovation and sustainability. We chose to discuss the problem of smoking in Romania, a widespread phenomenon among teenagers and young people. The diseases associated with smoking generate significant costs (waste) for the Romanian healthcare system; therefore the system's sustainability is affected. We then demonstrate how effective prevention and the introduction of desired behaviors related to health may work better if we use small, incremental and non-disruptive innovations in order to change the behavior of teenagers and young people about smoking. The proposed innovations are based on the need to better understand the psychological mechanisms of smoking and how teenagers and young people relate to it. In the case of teenagers, we suggest creating a different type of message - the sticky message - while, in the case of young people, we propose activating their responsibility by creating and/or facilitating the use of appropriate tools for health monitoring, but also by structural changes in the work place. Finally, we argue the need to change the financing of prevention and health promotion programs, by reorienting the health contribution paid by employees in accordance with their own needs, interests and priorities.
\end{abstract}

Keywords: sustainable healthcare system, disruptive and non-disruptive innovation, desired behaviors, sticky message.

\section{Introduction}

By sustainable healthcare system we understand that system that ensures the right balance between the cultural, social and economic areas - an environment designed to cover the individuals' health needs (from the promotion of health and preventing illnesses to restoring health and dying). A sustainable health system leads to optimal health and optimal health outcomes, without compromising the ability of future generations to take care of their own health and needs. Moreover, a sustainable health system is a complex one, a multi-stakeholders system with the

Cite this Article as: Adela Coman and Ana-Maria Grigore (2017)," Innovation as a Driver of the Sustainable Healthcare Systems: The Case of Romania ", Journal of Innovation \& Business Best Practice, Vol. 2017 (2017), Article ID 706791, DOI: 10.5171/2017.706791 
ability to mobilize and allocate resources on the long term so that the needs of the present and future population can be covered (Prada et al, 2014).

However, the system's sustainability is not influenced only by environmental factors, but also by politics, since political decisions are those to impose fiscal constraints in a country. The size of budgets, budget allocations on destinations and the priorities of the national health system are all decided by the political factor.

According to some authors, sustainability is linked more to improvement and innovation than to the status-quo (Herzlinger, 2006). Sustainability requires creativity and flexibility to adapt to changes in the social, economic and political environment, but also to changes in the population's demand for health services. Sustainability is thus a complex phenomenon that requires an innovative, multiple and integrating approach.

A phenomenon that challenges the sustainability of health systems, by the effects caused on health, is smoking. The adverse effects of smoking are well known and widely documented in the literature (Bjartveit, Tverdal, 2005; Stephenson et al, 2006; Auger et al, 2011). During childhood and adolescence, smoking creates serious health problems, such as: cough, respiratory diseases and even retard in lung development (Arday, Giovino and Schulman, 1995). Early smoking is often associated with the risk of developing tobacco dependence in adulthood. Teenagers are the target of anti-smoking and prevention advertising campaigns supported with a large amount of money by the state, but their effectiveness is low. Why are the anti-smoking campaigns ineffective? One reason could be the poor understanding of the psychological mechanisms that lead teenagers to smoke (Gladwell, 2000).

Smoking is a threat to the sustainability of health systems because of the high costs for treating diseases caused by smoking. Therefore, according to a study of the US Department of Health, 25\% of adolescent smokers are complaining of health problems such as asthma and allergies, but also various forms of cancer.

Under these circumstances, health systems face two contradictory trends: on the one hand, it is the need to support a growing demand for medical services and, on the other hand, the need to reduce costs in the system. In order to reconcile these two types of constraints, prevention and health promotion programs could be of real help, along with financing models and structures that induce desired behaviors among consumers, especially teenagers and young people.

This work is structured as follows: in the first part we discuss the conceptual framework of sustainable health systems, as well as the role of creativity and innovation in healthcare. Then, we analyze two pillars of the sustainable health systems, namely the prevention and health promotion programs and the consumers' desired behavior patterns and their financing. In the second part of the paper we discuss the problem of smoking in Romania, especially among teenagers and young people. By decoding the psychological mechanisms that explain why smoking is tempting and addictive for young people, we address the types of innovation that could be used to obtain desired behaviors in the case of Romanian teenagers and young people, at the individual and organizational level. Finally, we argue on the need to change the health system financing method in Romania envisaged as a disruptive innovation, designed to support two basic components of the sustainable health system, namely the prevention and health promotion and introduction of a healthy behavior among teenagers and young people.

\section{Sustainability and Innovation in Health:} A Literature Review

According to specialists (Prada et al., 2014), there are four principles underlying sustainable health systems (Fig. no. 1), namely:

- Responsibility for results or, in other words, act on the social, physical, cultural, organizational, 
political and environmental factors affecting the sustainability of the health system which can improve system performance;

- Deliver value in exchange of collected money. A fair value for money in the health system is translated, in economic terms, in obtaining better results with the same money. Thus, waste is removed, the system becomes more efficient, innovation is stimulated and results improve.

- Equitable access to medical services. The way in which this principle translates in everyday life affects the population's health and may undermine confidence in the system. Political support is also necessary to operate a sustainable health system.

- The principle of adequacy (resources-quality of services results). Proper translation of this basic principle in health means that the best resources - financial, human and technological - are used at the right moment to deliver that type of services aimed at obtaining the best results (principle of adequacy).

According to Fineberg (2012), a sustainable health system has three key features: affordability for patients and families, for employers and government (assuming that employers and the government rely on individuals as consumers to obtain the necessary resources for the health system); acceptability of the parties involved (including patients and professionals in the field); and adaptability, because health and health systems are not static.

A number of six key factors (Fig. no. 1) should be considered when discussing the health system sustainability (Prada et al, 2014).These are:

\section{Effective disease prevention and health promotion;}

This implies focusing on a better control of chronic diseases that may, according to statistics (National Statistics Institute, 2015), absorb approximately
$42 \%$ of the total direct medical expenses and, on the other side, on the prevention and management of health risk factors. Prevention requires interventions at individual level (related to smoking, alcohol, obesity), at organization level, in order to change the way in which people perceive their own health and at national level (interventions in the financing mechanism).

\section{Higher effectiveness of the health system through/with the help of advanced technologies}

According to statistics (National Statistics Institute, 2015), in Romania approximately $20-40 \%$ of the resources allocated to the health system are wasted because of the operational and clinical inefficiencies. According to specialized literature (Berwick, Hackbarth, 2012), the sources generating waste in the health system can be: failure to adopt the best medical procedures or their poor execution (leading to repeated hospitalization); lack of coordination of the health services (there is no integrative approach of the patient, as he/she is treated for one condition, while the others are omitted, leading to repeated hospitalization); excessive treatment (recommended by the doctor, but useless for the patient, which turns the doctor into a service seller); administrative complexity (inappropriate legislation and regulations that generate inefficiency); practice too high or too low prices for the services (and for medication) that deviate significantly from the market price; fraud and abuse (from bribes given to hospital managers for the purchase of materials and equipment and ending with money and goods offered by patients to doctors and nurses to receive a proper treatment). All these waste generating sources can be found, to a greater or lesser extent, in the Romanian health system. According to the same authors (Berwick, Hackbarth, 2012), the widespread introduction of informational technologies and tools already created (for example: the electronic medical records of patients) may contribute to the reduction or even elimination of waste. Using the latest technologies also creates supplementary value in the health system, which makes its 
implementation extremely necessary. In other words, technologies are those that ultimately contribute to shifting focus from the system's costs to creating value in the system.

\section{Funding models to lead to desired behavior change;}

The way in which we finance health services is an important element when talking about sustainability. The chosen financing model is essential to achieve the sustainability of services because it can determine a powerful motivation for change in the system. If the services financing model is not well designed, it can lead to inefficiency and waste.

Worldwide, the rising costs related to health are perceived as a threat to the system's financial sustainability. In Romania, health expenditure growth rate is higher than the growth rate of the gross domestic product (National Statistics Institute, 2015), and this trend is likely to continue if we consider the accelerated aging of population and the increased demand for medical services. If expenditures for health shall steadily exceed the economy's growth, then we shall have to discuss ethical issues, such as: how normal/moral is to finance from public money anti-smoking, anti-alcohol or anti-drugs health programs? Can these programs be better managed at national or local level? How can we induce another type of behavior among tobacco/alcohol/drugs consumers so as to reduce costs associated with ilnesses caused by excessive consumption of tobacco/alcohol/drugs?

Therefore, the key question is: how much should we spend on prevention programs and how, so that they can produce results?

$$
\begin{aligned}
& \text { 4. Promoting creativity and } \\
& \text { innovation (to help boost }
\end{aligned}
$$

$$
\begin{aligned}
& \text { productivity and improve } \\
& \text { quality of services); }
\end{aligned}
$$

It is known that indicators such as life expectancy and productivity can be improved through innovation. But for this to happen it is necessary to create strategies to improve understanding (how innovation operates in health), know-how and the system's capabilities.

\section{Optimal development and adequate support for the human resource in the system;}

In Romania there is a deficit - which became chronic in recent years- of qualified human resources, doctors and nurses. Health trends - aging population, development of new pathologies, etc. require the formation of multidisciplinary teams. In other words, today we cannot talk about progress in medicine without talking about interdisciplinary collaboration. Some authors (Edwards, Kornacki, Silversin, 2002) even speak of the need to train doctors in leadership skills or to develop the social element of the medical profession, because it can help reduce stress and the "burden" felt by doctors in the workplace. These are the reasons why the health system should pay particular attention to the training and development of well-prepared health professionals, but also to offer the necessary support for them to be able to work in the best conditions (in research, in specialized clinical practice, etc.).

\section{System alignment with the determinants of health}

"A public health system is based on choice. Eventually, the system is sustainable to the extent that the public and politicians believe it can and must be sustainable" says the Report on sustainability of the Conference Board in 2014. 


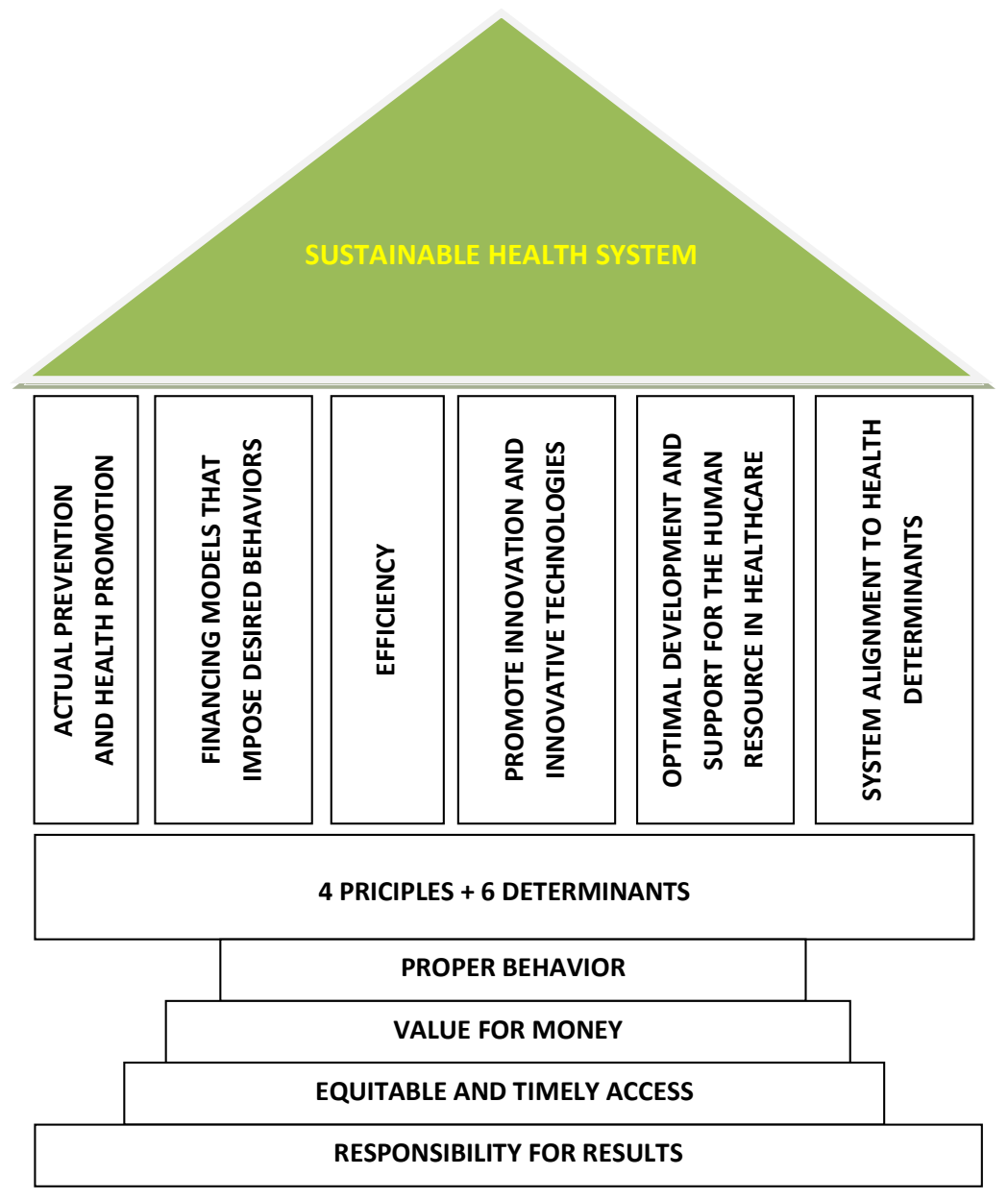

Fig. no. 1: Sustainable health system

Source: Adapted from The Conference Board of Canada, 2014

\section{What is Innovation in Health?}

Innovation may be defined as an intentional introduction and application within a role, group or organization of ideas, processes, products or procedures, new to the relevant unit of adoption, designed to significantly benefit the individual, the group, the organization or wider society (West, 1990). This definition is accepted by a great number of researchers in the field (Anderson et al, 2004, Herzlinger, 2006), because it includes the three most important characteristics of innovation: novelty, an applied component and a pursued benefit
(Lansisalmi et al, 2006). According to this definition, innovation in health consists of new services, new ways to perform work and/or new technologies (Lansisalmi et al, 2006). From the patient's perspective, the desired benefits are either to improve health or to reduce the suffering caused by the disease (Faulkner and Kent, 2001). The Advisory Committee on Measuring Innovation in the $21^{\text {st }}$ Century (2007) defines innovation as "the design, invention, development and/or implementation of new or modified products, services, processes, systems, organizational structures or business 
models in order to create new value for consumers and financial gains for the company."Varkey et al, (2008) define innovation as the successful implementation of new ideas in a way that creates value for certain stakeholders or for all.

Innovation may be regarded, according to its impact on stakeholders, as disruptive and non-disruptive. Non-disruptive innovations (Moore, 2004) also known as incremental (Hamel, 2000), evolutionary (Govindarajan, 2007), linear (Hamel, 2000), or supportive (VHA Health Foundation, 2006), improve something that already exists but in a way that opens new opportunities or solves current problems (Harvard Business Essentials, 2003). Christenssen et al (2004, p. 28) suggest something else: they say that innovation is "anything that creates new resources, processes or values, or improves the resources, processes or values already existing in the company." In short, innovation is the recognition of something new that shall hopefully work better.

Disruptive innovations, also called radical (Harvard Business Essentials, 2003), revolutionary (Govindarajan, 2006), transformational or non-linear (Hamel, 2000), refer to innovations that disrupt old systems, create new players and new markets while marginalizing the old ones, and give value to stakeholders that implement and adopt innovation.

Innovation in health typically occurs on three levels, namely: product, process and structure (Varkey et al, 2008). The product is what the client pays for and, usually, consists of goods and services (for example, innovations in clinical procedures). Innovative processes are innovations emerging in the production or delivery method. According to Varkey, the consumer does not pay directly for the process, but the process is necessary to deliver the good or the service. Therefore, an innovative process would be a change in the production or delivery of a product that allows a significant increase in value for one or more stakeholders. Structural innovation usually influences the internal and external infrastructure and creates new business models.

In short, innovation in health may be defined as the introduction of a new concept, idea, service, process or product in order to improve the treatment, diagnosis, education, result, prevention and research and on the long-term - improve quality, safety, results, efficiency and costs in the system.

Regina Herzlinger mentions that there are three types of innovations that may contribute to creating a sustainable health system, i.e. a system with better results and lower costs (Herzlinger, 2006). The first type of innovations changes the way in which consumers buy and use health services. The second type of innovations uses technology to develop new products and treatments in order to improve healthcare services. The third type of innovations generates new business models, especially models involving vertical and horizontal integration of various organizations and activities.

In this section we shall deal only with the first two pillars of the sustainable health system, namely the effective prevention and health promotion, as well as the funding of models that lead to desired behaviors among the population. To illustrate how prevention works (or not), and the desired health behaviors are installed (or not) in the system, we discuss the problem of smoking in Romania, a risk factor that continues to threaten especially the health of teenagers and young people, in the same time producing high costs/losses in the system.

\section{Smoking among Teenagers and Young People in Romania}

\section{Some statistics}

"Children inspire the future, the future does not inspire tobacco" (Diana Paun, state councilor, radio interview, September $8^{\text {th }}$, 2016). This is the title of the campaign initiated by the Romanian Government which therefore seeks to find the best solutions to reduce smoking among 
children and young people. The Government wishes 2035 to be the year of the first tobacco-free generation in Romania. The urgency of the campaign was imposed by recent statistics which show an alarming reality: $5 \%$ of 11 years old children, $7 \%$ of 13 years old children and $37 \%$ of 15 years old children have tried a cigarette; $29 \%$ of teenagers of $15-16$ years old smoke regularly.

How much do Romanians smoke and how much money is spent on cigarettes?

In 2015, Romanians spent an average of RON 94per month per household to buy cigarettes, tobacco products and smoking accessories, according to data presented by the National Statistics Institute (INS) in the study "Coordinates of living standards in Romania," cited by the newspaper "Weekend Adevarul." This amount (the average of RON 94 per month per household) is RON 6 higher than the average in 2014 (RON 88.3). The good news is that there are regions where costs on tobacco per household decreased.

Smokers spend about 5\% of their monthly budget to buy cigarettes, the amount being in slight increase in 2015 compared to 2014. In Bucharest and in the West of the country more money is spent on tobacco, and in Moldova and Oltenia regions the lowest amounts, official statistics show.

What worries is the trend of increased spending on tobacco per household, trend which is manifested in 7 of the 8 development regions in Romania (the only exception is the North-East region where this indicator has slightly decreased in 2015 compared to the previous year).

A study conducted in January 2016 in Romania on a sample of 2074 individuals above 18 years old, shows us how much Romanians smoke. Therefore, according to the study, one third of the people aged between 18 and 50 years old smoke almost a pack of cigarettes daily; smokers over 65 years old smoke between 6 and 10 cigarettes daily; the share of people who smoke more than two packs of cigarettes every week is higher among respondents aged under 35; women smoke between 1 and 10 cigarettes daily in a higher proportion than men. The main reason used by Romanians, when they are asked why they are smoking, is stress. 


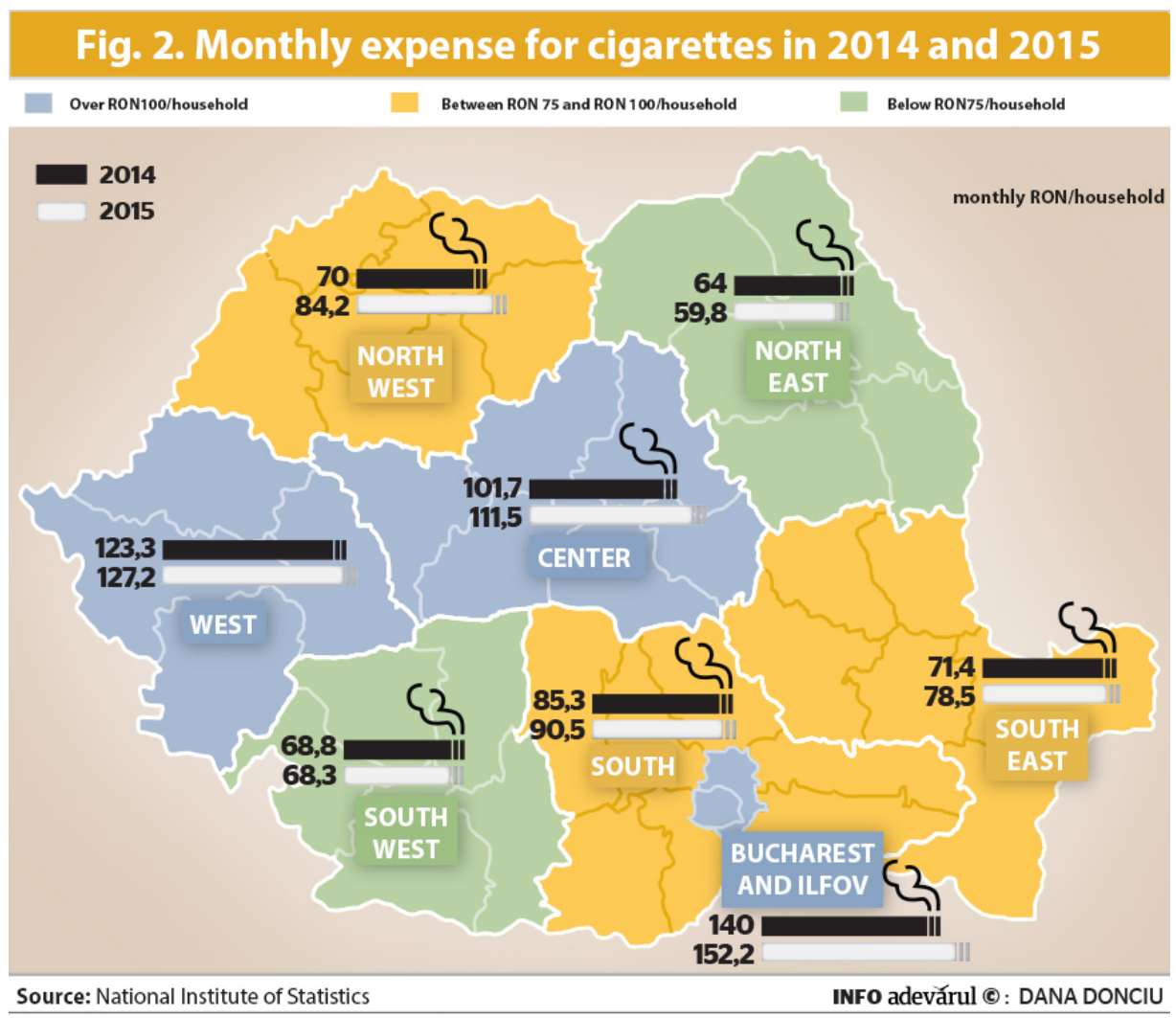

Fig. 2: Tobacco map in Romania (consumption and costs) 2014-2015

\section{Psychological causes and mechanisms that explain the "magic" of smoking for teenagers and young people}

Classical theories start from the premise that the decision to smoke is voluntary and based on the available information (Ajzen, Fishbein, 1980).

A factor that predicts smoking and that the anti-smoking advertisements take into account is related to expectations, namely the beliefs on the potential gains and losses which follow any action (for example: if I smoke, is it likely to make lung cancer?). Resulted expectations predict the use of tobacco by teenagers, as well as their intentions related to it, as demonstrated by multi-disciplinary and longitudinal studies (Morgan and Grube, 1989; Botvin et al, 1992). However, studies evaluating the impact of anti-smoking campaigns conclude that the anti-tobacco advertising targeting both the effects of smoking (in the short and long run) on health, and the consequences such as unattractiveness (e.g.: yellow and stained teeth), death and illness (Pechman and Goldberg, 1998), are inefficient. Why are these advertising campaigns inefficient?

We believe that, in the case of teenagers, the smoker's personality cannot be overlooked. We also know that the teenagers' impulse to buy a product or the interest for a certain situation lasts very little time. But, if they are repeatedly exposed to the same type of advertising, their behavior may change: the teenager follows the language and behavior of the hero in that advertising and tends to imitate it, seeing that behavior as normal. If we put together all features of extrovert and admired teenagers - mistrust, sexual precocity, honesty, impulsiveness, indifference to others' opinions, looking for thrills - we obtain an almost perfect picture of the type of person that teenagers are attracted to. These people are cool. But 
they are cool not because they smoke; they smoke because they are cool. These characteristics of rebellion and impulsivity, risk-taking and indifference to others' opinions, precocity and lack of fuss attract teenagers, urging them to turn to what embodies rebellion and risk, indifference and precocity: the cigarette. This observation may seem simple and obvious to many, but it is absolutely essential to understand why war against smoking has failed worldwide (Gladwell, 2000).

What can be done to prevent teenagers from becoming heavy smokers? Gladwell suggests that it is not a good idea to stop teenagers from imitating those whom they consider models - i.e. the rebels, impulsive, those who take risks, in a word the cool ones. To follow their parents' advice? Not a good idea either. Why? Because parents play a rather passive role - they provide the genes which may be favorable or not to smoking. And, from the social perspective, it was demonstrated that parents are unable to exert any influence on their children, most of the times. Under these circumstances, what would be the best way to address this issue?

Rowe (1994) and Harris (1998) show that the process by which teenagers are infected with the smoking disease is exclusively linked to what we call today the reference group, or group of colleagues and friends to which teenagers choose to refer to. Smoking in the case of teenagers speaks about what it is like to be a teenager, about shared emotions, about an expressive language and the language of adolescence, most of the times incomprehensible and irrational to outsiders. How can we intervene, under these circumstances, in order to make a difference? Harris observes that it is useless to tell teenagers that there are health risks associated with smoking. That will make them smile and "bury" you and your campaign altogether. That is just propaganda and adult arguments. And precisely because adults do not agree with smoking - because there is danger in it and because smoking is disgraceful and shameful - for all these reasons combined, teenagers will want to smoke and... they smoke.
Therefore, so far, it is not well known what type of content an anti-tobacco advertisement should have to really influence teenagers and make anti-tobacco campaigns more effective.

Some suggestions for designing better antismoking ads

We could try new educational programs, for teenagers, to include explicit measures to prevent smoking. But such programs have not led to the desired results: teenagers get bored quickly when speeches start with "is it wrong to..." or "look what happens to you if you keep smoking...." Moreover, inducing fear is rather counterproductive and therefore prohibited by the Romanian legislation (Coman, 2013). In this context, prevention measures considered by educators should focus on a different approach, built on phrases like: "I am strong because I want/can resist temptation"; "I am able to achieve whatever I intended (quit smoking)"; "no one can take decisions for me (how I live my life)"; "I know my life, health and career depend on the choices I make today," etc. In other words, we believe it would be necessary to shift the focus from the classical Pavlovian education programs in terms of prevention (if you do this...you will have to deal with that...) to building a behavioral model centered on self-respect and (increased) self-esteem that teenagers experience when they become aware of the fact that they can take control of their own lives.

As already shown, smoking among teenagers is a matter of behavior, a personal choice: teenagers want to show the world they are cool. Anti-smoking ads created so far failed to produce the desired effect. Why? Because their messages are not at all sticky for young people: they do not talk about adolescents, about what they really want. In the anti-smoking messages there are no inspiring heroes, no characters they can identify themselves with. And because the creators of such messages do not know the psychological mechanisms that make teenagers smoke, they cannot talk the teenagers' language. In other words, we need a better understanding of the smoking phenomenon, and in order to change 
behaviors, we need another type of messages. In the case of teenagers, the sticky message is the key.

We need a message to clearly show that non-smoking teenagers are also cool. In other words, we need to create a story where the hero is a charismatic, rebellious and... non-smoking teenager. Who is admired precisely because he does not smoke. Who takes risks, yet he does not smoke. Who is also respected by friends, colleagues and society. It is cool not to smoke, this should be the message!

And yes, we should talk about it with humor, stressing the fact that society tolerates smoking less and less. By showing that teenagers have the ability to resist any temptations, including smoking, they are cool. By fighting addictions and succeeding on their own they may prove themselves and the world they are strong and cool.

\section{Youngsters and activating responsibility}

For young people who have a job and smoke (for various reasons: stress, fatigue, depression, routine, etc.), there are two levels of action: an individual level and an organization level.

According to some specialists, young people, unlike teenagers, deliberately choose to smoke (Lansisalmi, 1990). For teenagers, smoking is a kind of virus: it is contagious and it spreads at lightning speed. For young people, however, smoking is a conscious choice: they choose to expose themselves to the risk of getting sick. Losses (health wise) seem, however, smaller than the benefits that smoking brings to young people: less stress, less irritability, and even a state of good (relative and for a short period of time). In their case, to convince them to quit smoking, the key seems to be activating responsibility.

At individual level, young people have at their disposal a variety of tools they can use if they want to change their behavior and move towards a healthier lifestyle. For example, a particularly useful tool to quit smoking is the IndiGO platform (Individual Guidelines and Outcomes). The platform is owned by a company called Archimedes and is based in San Francisco. This tool uses 30 variables specific to each patient/consumer (laboratory tests, biomarkers, demographic factors, history of illnesses and medication) and determines both the potential risk to get ill and ways to reduce the perceived risks (e.g. risks associated with smoking) through specific activities. Studies show that direct confrontation with the health-related risks makes the individual change his/her behavior and become more responsible (to quit smoking). The United States shall endeavor to correlate the electronic health records of patients with IndiGo because it was found that patients who can see their IndiGo score (which shows the risks of getting ill under the given circumstances) are 7 times more responsible when choosing their lifestyle compared to those who, for various reasons, are unwilling or unable to do so (Kaiser Permanente, Center for Total Health, 2016).

If, at individual level, the solution to quit smoking is activating responsibility, at organizational level structural changes should be operated. Thus, employers could create a less stressful organizational climate, by including among the benefits associated with the job, some wellness programs addressed to employees, or providing a relaxation room where employees can have access throughout the day. If it is true that a happy employee is a productive employee, then employers could resort to means to encourage the employees' creativity, by offering the employee a (paid) day a week in which they can work on a personal project. That is what happens at Google. One day for you, as an employee, can mean new ideas to follow, increased loyalty to your team and the company, but also a higher level of satisfaction.

Therefore, behavioral changes may be supported by different methods: in the case of teenagers, creating a different type of message and another type of hero, cool and non-smoker (non-smoker, but cool precisely because he is a non-smoker); in the case of young people, activating responsibility amid enabled awareness of the need to adopt a healthy lifestyle (personal choice) and a more friendly organizational climate for the employees. 
These innovations (a sticky message and an open work environment) do not produce changes in the health system. Why? Because this type of innovations is nondisruptive. They are rather small, incremental innovations that, under certain circumstances, can change behaviors.

But for things to really change in the system and to successfully manage to induce the desired behaviors, we need the so called disruptive innovation, i.e. that type of innovations that disrupts the system (in a good way), creates new players and new markets and gives value to all stakeholders. Such innovation could be directing the health contribution paid monthly by the employees $5.5 \%$ of total earnings) to destinations of their choice. Thus, employees could choose to become involved (or not) in programs of interest for them, with the possibility, in the end, to ascertain (personally) and to directly evaluate the result.

Here are some advantages of this method of system financing:

- Better control on how money is spent represents what we could name "the hard core" of the healthcare system;

A better control means a higher degree of transparency in spending funds, but also a better alignment of the available resources to the individual's health needs. According to Antohi (2013a), The National Unique Social Health Insurance Fund (the main funding source for the Romanian health system) proved to be financially unsustainable (it recorded increasing budgetary deficits in the past ten years). Moreover, total expenditure on health per capita placed Romania last among EU member states, a phenomenon linked to low health indicators of the population. In this context, Antohi (2013a) suggests that increased resources be made available in the system by bringing funds from private sources. Therefore, by developing the private element (private health insurance and co-payment mechanisms) competition would increase between health services providers, resource spending transparency would significantly improve and services offered to patients would be of a better quality.

- An increased efficiency in the system: consumers may select only the services offering a fair-value;

Therefore, poor quality services shall be in time removed from the market, which means that suppliers who do not deliver value to service consumers will disappear. This could also contribute to increased competition between service providers, new and old, that will want to provide the best services, at the best possible price (a fair price for the consumer, but also for the service provider).

An interesting approach in this respect (increased efficiency in the use of health resources) can be found in the work "Technical Efficiency in the Use of Health Care Resources: A Cross-Country Analysis" (Anton, 2013b). The author discusses the technical efficiency (the relation between inputs-labor, capital and equipment - and results obtained in health) from a comparative perspective. Thus, two indicators were considered, namely infant mortality and life expectancy at birth. Calculations showed that only 6 countries out of the 20 analyzed (in Eastern Europe and the Commonwealth of Independent States) use their resources efficiently, and 11 states are inefficient both in the way they spend resources allocated to the health system and with respect to the results obtained (high rates of infant mortality and reduced life expectancy compared to economically developed countries in the European Union). Romania is, from this perspective, in the category of countries with a modest technical efficiency (poor health results in relation to resources invested) (Antohi, 2013b). Therefore, increasing the quality of health services provided should become a priority, analyzed in relation to the costs involved and the results obtained.

- Prevention programs could get special attention, including in terms of the amounts allocated to them: many consumers will want to contribute financially because, psychologically, they will feel they are doing the right thing/ it is in their power to intervene to stop or 
reduce excessive consumption of tobacco/alcohol or drugs; or, if they belong to a category of individuals affected by a chronic illness, they will want to support that program which supports the chronically ill (e.g.: cardiac patients, those with rare diseases, etc.).

Disruptive innovations are difficult to introduce in the system because the Romanian healthcare system tends to maintain its status quo. But, in Romania, popular wisdom says that "if you change financing, you change the system." And if we look at the Western countries, we shall notice that they have also introduced, in time, changes in the system's financing, offering more power to consumers and challenging them to become more responsible towards their own health (e.g.: Canada, Denmark and, more recently, Italy).

\section{Conclusions}

In this paper, we discussed innovation as a driver of the sustainable healthcare systems, by sustainability understanding a better health condition of the population and lower costs in the system.

We showed that at the basis of a sustainable health system there are 4 principles (responsibility for results, equitable and timely access to desired services, value for the money spent and alignment between resources - services provided - results) and 6 key factors (or lines of action) that support the system's sustainability (actual prevention and health promotion; financing models that induce desired behaviors; efficiency; promoting innovation and innovative technologies; optimal development and support for the human resources in healthcare; the alignment of the system with the health determinants).

We chose to talk about prevention and about the funding of models that induce desired behaviors and we showed that, for the health system to work better and in the same time, with lower costs, we need to introduce innovative changes at individual, organizational and national level. As a case study, we chose to analyze the problem of smoking among teenagers and young people in Romania. Our findings are based largely on relevant studies about smoking (psychology, economics, behavioral studies). To sum up, these are: programs for the prevention of tobacco use are not effective because those who create them (national and local authorities) are unfamiliar with the teenagers and young people's behaviors, and because they do not know much about their psychology and way of thinking, the anti-smoking advertisements, as part of national programs to combat smoking, do not work; for each category of consumers (smokers) there must be a specific approach: for teenagers, creating a new type of hero, cool and non-smoker, who is cool because he is a non-smoker; for young people, activating responsibility towards their own health could lead to the desired result if young people, on the one hand, have access to appropriate tools to help them take better decisions regarding their own lifestyle and, on the other hand, they have access to a friendly, less stressful working environment.

Therefore, by introducing small, nondisruptive innovations (sticky messages for teenagers; appropriate tools for activating young people's responsibility) we can increase the chances of obtaining the desired behaviors in teenagers and youngsters: stop smoking or at least significantly reduce smoking (decrease the number of cigarettes consumed daily). In short, by introducing innovations at individual and organizational level, the phenomenon of smoking in Romania could switch downwards from its growing tendency.

However, the desired behavioral changes must be supported through changes in the financing mechanism of the healthcare system. Specifically, we demonstrated that the innovation called directing the health contribution monthly paid by the employees towards the destination/destinations of their own choice could be the type of (disruptive) innovation which greatly increases the probability of obtaining the desired outcomes. Why? Because the consumers know best their own needs, interests and 
priorities. In other words, if you offer them access to their own contribution to the healthcare fund, they may choose to finance the prevention programs they are interested in (directly or indirectly; at individual or community level) or the programs for the treatment of chronic diseases, etc. Whatever the destination of the money, results shall appear: a better control of costs, better services and, overall, an increased efficiency of the healthcare system. In other words, we could have a system that works better, at lower costs.

Therefore, we can say now with certainty that innovation is the engine of sustainable healthcare systems. Innovations in health generate the expected results on one condition, namely: in the center of all decisions on health should always be the consumer. To address sustainability means (among other things) to change behaviors. We could start by trying to better understand his/her way of thinking, to analyze how he/she relates to others in more profound ways while helping people make the best choices regarding their own health.

\section{References}

Agostinelli, G., Grube, J. W. (2003) 'Tobacco Counter-Advertising: A Review of the Literature and A Conceptual Model for Understanding Effects'. Journal of Health Communication, vol. 8, 107-127.

Ajzen, I. (1987) 'Attitudes, Traits and Actions: Dispositional Predictions of Behavior in Personality and Social Psychology'. In L. Berkowitz (Ed), Advances in Experimental Social Psychology. Academic Press, NY, 1-63.

Ajzen, I. (1991) 'The Theory of Planned Behavior'.Organizational Behavior and Human Decision Processes, 50, 179-211.

Arday, D., Giovino, G. A. and Schulman, J. (1995) 'Cigarette Smoking and SelfReported Health Problems among US High School Seniors, 1982-1989'. American Journal of Health Promotion, 10, 111-116.
Anderson, N. C., De Dreu and Nijstad, B. A. (2004) 'The Routinization of Innovation Research: A Constructively Critical View of the State-of-the-art Science'. Journal of Organizational Behavior, 25, 147-173.

Anton, S. G. (2013a). 'Solutions for Sustainable Financing of the Romanian Healthcare System'.Journal of Social Economy, vol. III (2):102-112.

Anton, S. G. (2013b). 'Technical Efficiency in the Use of Health Care Resources: A Cross-Country Analysis'. Scientific Annals of the Alexandru Ioan Cuza University of Iasi Economic Sciences, 60(1): 31-42.

Auger, P., Burke, P., Devinney, T. M. and Louviere, J. J. (2003) 'What Will Consumers Pay for Social Product Features?'Journal of Business Ethics, 42(3): 281-304.

Auger, N., Daniel, M., Knauper, B., Raynault, M. F. and Pless, B. (2011) 'Children and Youth Perceive Smoking Messages in an Unbranded Advertisement from A NIKE Marketing Campaign: A Cluster Randomized Controlled Trial - BMC'. Pediatrics, 11-26.

Berwick, D. M. (2015) 'Disseminating Innovations in Health Care'. JAMA,289-295.

Berwick, D.M., Hackbarth, A.D. (2012) 'Eliminating Waste in US Health Care', JAMA, 307(14): 1513-1516.

Bjertveit, K.,Tverdal, A. (2005) 'Health Consequences of Smoking 1-4 Cigarettes per Day'.Tobacco Control, 14: 315-320.

Edwards, N., Kornecki, M.J., Silversin, J. (2002) 'Unhappy Doctors: What Are the Causes and What Can Be Done?'BMJ, vol. 324 (7341): 835-838.

Coman, A. (2013) 'Some Legal Issues in Consumer Behavior Research', In M. Dutu, M. Tomita (Eds) National Conference: The New Romanian Civil Code, Two Years after its Entry Into Force. Theoretical and Practical Problems. Medimond: Italy, 217223.

Fineberg, H. (2012) 'A Successful and Sustainable Health System: How To Get 
There From Here'. The New England Journal of Medicine, vol. 366, 1020-1027.

Fuchs, V. R. and Sox, H. C. (2001) 'Physicians Views of the Relative Importance of Thirty Medical Innovations'. Health Affairs, vol. 20, 30-42.

Gladwell, M. (2000) 'The Tipping Point: How Little Things Can Make A Big Difference'. Black Bay Books: NY.

Govindarajan, V. (2016) 'The Importance of Strategic Innovation'.[Online].[Retrieved June, 15th, 2016].http://www.vijaygovindarajan.com/ 2006/.

Gupta, A. (2008) 'Prescriptions for Change'.The Wall Street Journal.[Online].[Retrieved October 20, 2016].http://www.wsj.com/articles/SB12 2426733527345133.

Hamel, G. (2000) 'Leading the Revolution'. Boston, MA: Harvard Business School Press.

Harris, J. R. (1998) 'The Nurture Assumption: Why Children Turn Out the Way They Do'. The Free Press.

Harvard Business Essentials (2003) 'Managing Creativity and Innovation'. Boston, MA: Harvard Business Review Press.

Herzlinger, R. (2006) 'Why Innovation in Health Care Is So Hard?'Harvard Business Review, 15-26.

National Institute of Statistics (2015) 'Coordinates of the Living Standards in Romania' [Online] Weekend Adevarul. [Retrieved June 15, 2016].http://www.insse.ro/cms/en/conte nt/coordinates-living-standard-romaniapopulation-income-and-consumption-2015

Kaiser Permanente, Center for Total Health blog.

https://centerfortotalhealth.org.15.03.201

6.

Lansisalmi, H., Kivimaki, M., Aalto, P. and Ruoranen, R. (2006) 'Innovation in Health Care: A Systematic Review of Recent
Research'. Nursing Science Quarterly, vol. 19, 66-72.

Mihaltan, Fl. (2011) 'Ce nu stie fumatorul roman'. Bucuresti: EdituraMedicala.

Moore, G. A. (2004) 'Darwin and the Demon: Innovating within Established Enterprises'. Harvard Business Review, vol. 82,7 .

Omachonu, V. K., and Einspruch, N. G. (2009) 'Innovation: Implications for Goods and Services'. International Journal of Innovation and Technology Management, vol. 2, 1-20.

Prada, G., Grimes, K. and Sklokin, I. (2014).'Defining Health and Health Care Sustainability'. Ottawa: The Conference Board of Canada.

Rowe, D. C. (1994) 'The Limits of Family Influence: Genes, Experience and Behavior'. New York: The Guilford Press.

ScoalaNationala de StudiiPoliticesi Administrative (2013) 'Bucurestenii si sanatatea. Sondaj la nivelul municipiului Bucuresti'.

VHA Health Foundation (2016).'The Power of Innovation'. [online]VHA Research Series. [Retrieved September 20, 2016]http://www.vhahf.org/portal/

Varkey, P., Horne, A. and Bennet, E. (2008). 'Innovation in Health Care: A Primer'. American Journal of Medical Quality, vol. 23, 382-388.

West, M. A. (1990).'The Social Psychology of Innovation in Groups'.InMichael West, James, L. (Eds) Innovation and Creativity at Work: Psychological and Organizational Strategies. Oxford: Wiley\&Sons, 309-334. 